\title{
Um Sobrevoo pelo Estado da Arte sobre Gênero e Sexualidade na Pesquisa
}

\author{
Tainá Regina de Paula ${ }^{1}$ \\ Eric de Jesus Porto ${ }^{1}$ \\ ${ }^{1}$ Centro Universitário de Mineiros, GO, Brasil. \\ ${ }^{1}$ Centro Universitário de Mineiros, GO, Brasil. \\ Cíntia de Sousa Carvalho ${ }^{1}$ \\ ${ }^{1}$ Centro Universitário de Mineiros, GO, Brasil.
}

\begin{abstract}
Resumo: Atualmente o Brasil se encontra em um cenário preocupante em termos de violações de direitos, sobretudo no que se refere às minorias sexuais. Tendo em vista que tal cenário produz intenso sofrimento, é importante que se construam espaços de pesquisa, discussão e reflexão que possam trazer maior densidade e visibilidade às problemáticas sociais que envolvam gênero e sexualidade. Neste sentido, este estudo, marcado pela perspectiva genealógica de Foucault, trata-se de uma pesquisa de revisão bibliográfica, cuja análise deu-se por meio de um estudo quantitativo, que foi construído a partir da análise das bases de dados SciELO, LILACS e Lattes. Tal análise teve por objetivo apontar como as temáticas relacionadas ao gênero e à sexualidade são abordadas nas produções das ciências humanas, especialmente na Psicologia. Diante dos resultados, constatou-se que a ciência psicológica não é uma das áreas mais envolvidas com o tema. No entanto, vale salientar que os estudos da Psicologia encontrados apontam para uma análise mais crítica e que aposta na produção dos sentidos, distanciando-se de uma perspectiva mais positivista.
\end{abstract}

Palavras-chave: Gênero, Sexualidade, Pesquisa.

\section{An Overview of the State of the on Gender and Sexuality in Research}

\begin{abstract}
Brazil is in a worrying scenario in terms of violations of rights, especially with regard to sexual minorities. Taking into account that this scenario produces intense suffering, it is important to construct spaces of data, discussion and reflection which relate to networks that evolve gender and sexuality. In this sense, this study, marked by the genealogical perspective of Foucault, is a bibliographical research, using a quantitative study, which was constructed from the analysis of the databases SciELO, LILACS and Lattes. This analysis sought to point out how gender and sexuality issues are approached in the humanities productions, especially in Psychology. It was found that the psychological science is not involved with this subject. However, it is worth mentioning that the studies of Psychology studied here point to a more critical analysis that defends the production of senses, distancing itself from a more positivist perspective.
\end{abstract}

Keywords: Gender, Sexuality, Research. 


\title{
Un Sobrevuelo por el Estado del Arte sobre Género y Sexualidad en la Investigación
}

\begin{abstract}
Resumen: Brasil se encuentra actualmente en un escenario preocupante en términos de violaciones de derechos, especialmente con respecto a las minorías sexuales. Dado que este escenario produce un sufrimiento intenso, es importante crear espacios para la investigación, el debate y la reflexión que puedan aportar mayor densidad y visibilidad a los problemas sociales relacionados con el género y la sexualidad. En este sentido, este estudio, marcado por la perspectiva genealógica de Foucault, es una investigación de revisión bibliográfica, cuyo análisis tuvo lugar a través de un estudio cuantitativo, que se construyó a partir del análisis de Scielo, Lilacs y Lattes. Este análisis tuvo como objetivo señalar cómo se abordan los temas relacionados con el género y la sexualidad en las producciones de las ciencias humanas, especialmente en Psicología. Dados los resultados, se descubrió que la ciencia psicológica no es una de las áreas más involucradas con el tema. Sin embargo, es digno de mención que los estudios de Psicología encontrados apunten hacia un análisis más crítico y que apuesten por la producción de los sentidos, alejándose de una perspectiva más positivista.
\end{abstract}

Palabras clave: Género, Sexualidad, Investigación.

\section{Introdução}

Atualmente, vivemos num cenário bastante preocupante em termos da violação de direitos na esfera das questões que envolvem gênero e sexualidade. A realidade brasileira apresenta números assustadores no que diz respeito à realidade LGBTT (lésbicas, gays, bissexuais, travestis e transexuais): de acordo com dados do Grupo Gay da Bahia (GGB) (2016), o Brasil é o país que mais assassina LGBTs no mundo. Só em 2016 foram um total de 343 mortes motivadas por LGBTfobia, colocando o Brasil como campeão de crimes contra minorias sexuais. Há mais mortes no Brasil do que em países em que há previsão de pena de morte contra a população LGBT.

Para termos uma ideia da dimensão deste problema, no ano de 2000, o número de homicídios era de 130, o que significa que em seis anos, a quantidade de homicídios mais que triplicou (GGB, 2016). Ainda neste mesmo estudo, consta que o estado de Goiás, lócus de produção desta pesquisa, se encontra também numa posição desfavorável: dos 343 homicídios no ano de 2016, 15 ocorreram no estado de Goiás, colocando-o na 7a posição (dos 23 estados e Distrito Federal). Já de acordo com o Relatório de Violência Homofóbica no Brasil, da Secretaria de Direitos Humanos, em 2013 (Brasil, 2016), Goiás ocupava a 15a posição, o que sugere um aumento substancial deste tipo de ato no estado.
Importante frisar que, como no país os atos de ódio contra as minorias sexuais não são tipificados como crimes, logo, não existem estatísticas governamentais neste sentido (os crimes, atualmente, são enquadrados de forma genérica como discriminação, injúria ou agressão), fato que aponta para a subnotificação destes casos. Isto é, o número de assassinatos acima mencionado, muito possivelmente, expressa apenas uma parte das reais violências que acontecem no cotidiano e das quais não temos notícia. Os dados da pesquisa do Grupo Gay Bahia (2016) foram coletados através de pesquisa hemerográfica, ou seja, com base em notícias publicadas em veículos de imprensa (mídia, internet e informações pessoais). Convém salientar a importância deste estudo no cenário nacional, visto que tais dados já foram usados como referência para elaboração do Relatório de Violência Homofóbica no Brasil, da Secretaria de Direitos Humanos, em 2013 (Brasil, 2016), acima mencionado.

Os tipos de mortes também revelam que há uma hierarquia da violência endereçada à população LGBTT, pois metade das pessoas mortas eram gays e cerca de $42 \%$ trans (travestis e transexuais). O número restante diz respeito às lésbicas, bissexuais e heterossexuais (que foram mortos por manter relações com transexuais, ou por serem parentes/conhecidos, ou ainda por terem sido confundidos com gays). Não obstante, há uma divisão espacial na tipificação das 
mortes, visto que as travestis são, no geral, assassinadas nas ruas e com arma de fogo, enquanto os gays sofrem por ataques domésticos, por meio de facas, fios elétricos, sufocamento. A maior parte das pessoas que foram mortas são jovens (entre 21 e 30 anos).

Outra realidade alarmante refere-se à violência cometida contra mulheres. Para Waiselfisz, (2015), apesar de vivermos no Brasil uma realidade distinta da anteriormente apresentada (há a criminalização da violência contra a mulher por meio da Lei Maria da Penha desde 2006, Lei ${ }^{\circ} 11.340$ e, mais recentemente, foi sancionada a Lei $\mathrm{n}^{\circ} 13.104 / 2015$, intitulada Lei do Feminicídio, classificando-o como crime hediondo), ainda assim, vivemos um cenário preocupante de acordo com o Mapa da Violência de 2015, onde Brasil ocupa o $5^{\circ}$ lugar no mundo no ranking de feminicídios, perdendo apenas para países como El Salvador, Colômbia, Guatemala e a Federação Russa.

A partir da implementação da Lei Maria da Penha, houve uma queda nos números do feminicídio, seguida de um acréscimo: em 2007, foi de 4,2 para 3,9 por 100 mil mulheres; mas, rapidamente, o feminicídio ultrapassou as taxas de 2006 nos anos subsequentes, que era de 4,2 por 100 mil mulheres, chegando ao marco de 4,8 em 2013 (Waiselfisz, 2015).

Em Goiás, os números também não são alentadores. No ano de 2013, o estado ocupava a $3^{a}$ posição no ranking de taxas de homicídios de mulheres por 100 mil habitantes, perdendo apenas para Roraima e Espírito Santo, e se igualando aos números de Alagoas (Waiselfisz, 2015).

No Brasil, o perfil das mulheres que mais morrem é bastante definido: mulheres e meninas negras (66,7\% dos feminicídios), especialmente entre 18 e 30 anos. As mortes geralmente são provocadas por força física, objeto cortante/penetrante ou contundente, e com menor participação de arma de fogo do que na comparação com os homicídios masculinos. Em sua maioria, os assassinatos foram cometidos no domicílio da vítima e por pessoas conhecidas (o que caracteriza maior incidência de violência doméstica e familiar entre as vítimas mulheres) (Waiselfisz, 2015).

Obviamente, o duplo cenário acima apresentado é produtor de intenso sofrimento psíquico que convém ser acolhido nas suas especificidades. Mas, o que há em comum entre estes dados? Percebemos que há uma ligação perniciosa entre a violência e as questões que envolvem o gênero e a sexualidade. Os atos violentos que desqualificam o outro em sua singularidade vão em duas direções: na primeira, no que se refere às identidades de gênero, há uma desqualificação do feminino em detrimento do masculino, legitimada pela desigualdade de gênero produzida pelo modelo patriarcal. A mesma desqualificação se dá em relação às identidades que não se fundamentam no binarismo homem e mulher como é o caso dos(as) travestis e transexuais. Na segunda, no que se refere à orientação sexual, há um rechaço de todo modo de amar e se relacionar sexualmente que não seja inserido no padrão heteronormativo. Assim, aniquilar o outro (física e simbolicamente) torna-se a solução para uma sociedade despreparada para acolher a diferença como parte fundamental da diversidade humana. É importante aludirmos ao processo de produção da LGBTfobia e da misoginia na cultura, posto que as hierarquias entre os seres humanos não nascem com os sujeitos, mas são produzidas socialmente.

Em tempos sombrios, de perda de direitos sociais fundamentais, é urgente que espaços coletivos como a universidade e demais ambientes sociais que lutam pelos direitos humanos afirmem sua posição de resistência política e ética frente aos retrocessos. Portanto, falar sobre gênero e sexualidade nestes territórios não constitui transgressão, mas antes responsabilidade social. Uma universidade crítica é aquela que se posiciona, que articula e faz pensar sobre os diversos temas do cotidiano e que atravessam a experiência dos sujeitos sócio-históricos.

Portanto, com este artigo buscamos compreender de que maneira as temáticas relacionadas ao gênero e à sexualidade estão sendo discutidas nas produções científicas nacionais recentes, tendo como foco principal a Psicologia. Assim, poderemos avaliar o engajamento social deste campo saber junto às temáticas supracitadas, bem como avaliar, de que formas a Psicologia produz narrativas acerca das questões de gênero e sexualidade. Entendemos que as produções discursivas científicas possuem efeitos performáticos e, para tanto, é necessário compreender quais mundos estamos a produzir a partir das afirmações que enunciamos.

\section{Método}

Este artigo, que busca apresentar os resultados da pesquisa intitulada "Entre ditos, não-ditos e interditos: reflexões sobre gênero e sexualidade na pesquisa científica", diz respeito a uma investigação de cunho 
quantitativo, tendo como estratégia metodológica a revisão bibliográfica. Num primeiro momento, foi produzida uma significativa revisão de literatura por meio de leitura, discussão coletiva de textos/artigos/ livros e produção de resenhas. A revisão bibliográfica foi realizada no intuito de conhecer e estudar algumas das principais referências no âmbito das discussões sobre gênero e sexualidade, mais especificamente as seguintes obras: "A história da sexualidade 1", de Michel Foucault (1988); "Gênero: uma categoria útil de análise histórica", de Joan Scott (1995); e "Problemas de gênero", de Judith Butler (2003).

Num segundo momento, foi realizado um mapeamento das publicações científicas produzidas no campo das ciências humanas, cujos temas refiram-se às questões de gênero e sexualidade, desde a virada do século até o momento atual (2000 a 2018). De acordo com o Conselho Nacional de Desenvolvimento Científico e Tecnológico (CNPq), as ciências humanas dividem-se em: Filosofia, Sociologia, Antropologia, Arqueologia, História, Geografia, Psicologia, Educação, Ciência Política e Teologia. Assim, foi possível conhecer qual o campo de saber possuía maior número de publicações na área, bem como detectar qual a expressividade da Psicologia neste âmbito.

Para quantificar os dados pretendidos, foram acessadas três plataformas de publicações científicas, a saber: Scientific Electronic Library Online (SciELO), Literatura Latino-Americana e do Caribe em Ciências da Saúde (LILACS) e Lattes. Na plataforma LILACS e SciELO, a pesquisa foi realizada com os seguintes descritores: Gênero e Sexualidade + área do saber (por exemplo, Gênero e Sexualidade Psicologia). No conjunto foi utilizado o filtro de informações como: Ano - 2000 a 2018; País - Brasil; Idioma - Português.

Na plataforma Lattes, devido ao fato de termos que analisar o currículo dos autores, o trabalho se tornou mais complexo. Na barra de pesquisa de busca da plataforma consideramos o mesmo esquema de pesquisa do LILACS e SciELO: Gênero e Sexualidade + área do saber (por exemplo, Gênero e Sexualidade Psicologia). A filtragem de pesquisa considerou Doutores e demais pesquisadores (Mestres, Graduados, Estudantes, Técnicos, etc.), nacionalidade brasileira e país Brasil. No Lattes foram analisados 50 currículos de cada área das ciências humanas definidas, até a $5^{\text {a }}$ página, visto que cada uma continha 10 currículos. A análise se estendeu para artigos completos publicados em anais de eventos, capítulo de livros, livros e artigos publicados em periódicos. A escolha pelo Lattes permitiu encontrar uma maior diversidade de produções científicas, para além dos artigos já indexados nas plataformas LILACS e SciELO.

Num momento subsequente, o foco se dirigiu aos trabalhos desenvolvidos pela Psicologia. Esta etapa da pesquisa foi dividida em duas categorias de trabalho: revisão bibliográfica e pesquisa de campo. As pesquisas de campo estiveram presentes em 40 trabalhos, que foram estudados e subdivididos nas categorias: número de publicação por estado; principais temas; gênero dos autores principais e dos autores secundários, base teórica da pesquisa; métodos empregados e população alvo do estudo.

\section{Resultados e discussões}

\section{Revisão teórica}

Foucault (1988) afirma que a sexualidade, até o início do século XVII, era tida como prática integrada aos hábitos sociais, gozando de visibilidade. Entretanto, em meados da época vitoriana, o tema passou a ser silenciado, tornando-se um grande segredo, principalmente de adultos heterossexuais.

Este silenciamento distanciou a sexualidade do universo dos prazeres, para submetê-la aos fins reprodutivos. A sexualidade passa a ser compreendida como prática privada, assim, os discursos sobre o sexo passam a ser percebidos como atos pecaminosos, principalmente quando mencionados sem prudência. Deste modo, a repressão sexual nasce por meio do controle da livre circulação da linguagem.

Para a manutenção destes interditos, a sexualidade entra nas práticas discursivas, para, então, através das palavras, controlar o agente sexual e seus comportamentos. A sexualidade, ao adentrar o campo discursivo, possibilitou que o sexo fosse objeto de análises de locutores selecionados (médicos, pedagogos, atores religiosos). No entanto, conforme afirma Foucault (1988), este aumento do discurso teve como efeito o controle das práticas, ao selecionar o que dizer e para quem dizer.

Deste modo, mesmo que se fale mais sobre sexo, esta visibilidade não produziu reconhecimento das diversas maneiras de vivenciar a experiência sexual, nem acolhimento dos modos singulares de experimentá-la pois, dentro das práticas discursivas já se têm instalado o legítimo e o ile- 
gítimo, ideais que foram construídos com base no padrão heteronormativo.

Em outras palavras, Foucault (1988) nos mostra como é necessário que desconfiemos do discurso de que hoje vivemos, muito mais do que outrora, uma liberdade sexual. Para ele, vivemos sim um universo em que se fala mais sobre sexo (vide os discursos midiáticos, por exemplo), mas que é, na verdade, uma falsa democracia. Esse falar, de algum modo, serve muito mais para sermos controlados (o que fazemos com nossos corpos, por onde andam nossos desejos) do que para sermos acolhidos em nosso modo singular de viver a sexualidade. Mesmo porque, já existe socialmente a ideia do que é legítimo e do que é ilegítimo em nossas práticas sexuais.

Neste sentido, Butler (2003) compreende que a compulsão à heterossexualidade como a única maneira permitida de manifestação do desejo, está relacionada à dificuldade social de reconhecer que há diferenças entre o sexo, gênero e desejo/orientação sexual. Além disso, considera que esta compulsão surge a partir do entendimento da biologia como determinante do ser humano, desconsiderando as dimensões biopsicossociais do sujeito. Assim, para a autora, para combatermos a compulsoriedade heteronormativa, seria necessário distinguir estas três dimensões, de modo que os argumentos biologizantes possam ser relativizados.

Por sexo, Butler refere-se a toda uma dimensão biológica dos corpos, diferenças fisiológicas e anatômicas existentes entre machos e fêmeas, basicamente definidas pelos órgãos genitais. $O$ gênero seria, então, o entendimento de que as diferenças sexuais biológicas (acima descritas) não são definidoras das identidades e dos comportamentos. $\mathrm{O}$ gênero é resultado de um intenso processo de educação social/política/cultural/religiosa/jurídica dos corpos e das subjetividades. Em outras palavras, as diferenças de gênero são aprendidas e produzidas socialmente. Tal processo, historicamente, tendeu a dividir os seres humanos de forma binária (masculino e feminino), entretanto, há outras identidades de gênero que se apresentam, atualmente, no cenário social (homem, mulher, travesti, transexual etc.). Já o desejo aponta para a orientação sexual, isto é, refere-se às escolhas afetivas e sexuais de cada sujeito, para onde (ou para quem) o desejo é direcionado (homossexual: pessoa que se relaciona com outra do mesmo sexo; heterossexual: pessoa que se relaciona com outra de sexo oposto; e bissexual: pessoa que se relaciona com pessoas do mesmo sexo ou do sexo oposto).

Não existe uma relação de subordinação entre sexo, gênero e desejo, são instâncias da experiência humana que possuem autonomia entre si. Tentar justificar a heteronormatividade a todo custo é uma maneira de reduzir outras possibilidades humanas de existência.

No que se refere ao gênero, as preocupações teóricas surgiram somente no século XX e foi a partir do movimento feminista e movimento gay que este termo passou a ser empreendido como ferramenta política. Como aponta Scott (1995), "gênero" é um termo amplo, que tem passado por diversas transformações. Para a autora, o gênero se refere a uma construção social das atribuições que qualificam o macho ou a fêmea, isto é, diz respeito às atribuições sociais endereçadas aos indivíduos.

Vimos que tanto a sexualidade quanto o gênero são marcadores sociais que sobrevivem, pois estão representados em discursos e práticas que, performaticamente, ensejam realidades. Assim, percebemos que a reiteração social discursiva tem força produtiva, logo, é necessário que nos debrucemos na análise daquilo que se apresenta na linguagem, para que possamos compreender em que termos as verdades sobre a experiência humana estão sendo construídas. O discurso científico foi selecionado como canal para esta análise, visto sua capilaridade e poder no cenário da esfera social.

\section{Gênero e sexualidade: as problemáticas no cenário brasileiro}

Se pararmos para observar o modo como o Brasil se organiza para pautar as questões de gênero e sexualidade, perceberemos um abismo. As famílias detêm direito à liberdade para educar seus filhos de acordo com seus preceitos (éticos-morais-religiosos-sociais). Portanto, ficaria sob responsabilidade do Estado apresentar elementos da cultura, na sua multiplicidade e complexidade, que não necessariamente seriam abordados de forma sistemática pelas famílias. Os mecanismos educativos, mais especificamente as escolas e universidades, deveriam, portanto, se responsabilizar por este trabalho, que não desqualifica os saberes familiares, mas que ampliam o espectro de questões presentes, sobretudo, pautando-se nos discursos científicos. 
Na prática, o que percebemos é que há uma dificuldade do estado brasileiro em se manter laico e democrático. Assim, há a pressão dos grupos conservadores (muitos deles religiosos), que buscam banir qualquer referência às questões de gênero e sexualidade no âmbito estatal, negando, assim, todos os alarmantes dados anteriormente apresentados. Vide o Projeto de Lei $\mathrm{n}^{\circ} 867 / 2015$, popularmente conhecido como "Escola sem Partido". A proposta deste projeto, de acordo com seu autor, deveria ser incluída em toda educação nacional, com o objetivo de garantir a neutralidade política, ideológica e religiosa. Afirma ainda que a escola deve respeitar o direito dos pais a que seus filhos recebam a educação moral que lhes aprouver, ficando a escola subordinada a estes preceitos.

Em última instância, este projeto de lei visa banir temas como gênero e sexualidade nas escolas, com a posição de que a discussão de tais conteúdos serviria para uma suposta doutrinação dos estudantes. Levantando a bandeira da neutralidade e da liberdade, o que este projeto de lei busca, na verdade, é impedir que outras formas de compreender as identidades de gênero e a orientação sexual sejam também incluídas no currículo. Caso as escolas fiquem impedidas de discutir tais questões, por exemplo, como enfrentaremos a LGBTfobia, o feminicídio, a misoginia e o machismo em nossa sociedade? Ao deixarmos de pautar estas questões como parte da reflexão crítica acerca da realidade em que estamos inseridos, não estaremos institucionalizando a violência? Omitir é também uma forma de amolar a faca destes homicídios. Entendemos que o não enfrentamento destas questões, seja num nível micro ou macropolítico, é também uma forma de produção deste cenário, questão que nos mobilizou na escrita deste texto, que busca engajar a Psicologia neste debate.

Atualmente, nas escolas, o tema "Orientação Sexual” é garantido por meio dos Parâmetros Curriculares Nacionais (PCN) (Brasil, 1998), mas como temática transversal ao currículo, isto é, faz parte de um currículo indireto que, no mais das vezes, acaba desaparecendo frente à avalanche conteudista que se apresenta nas exigências escolares. Na prática, observamos professores despreparados para lidar com tais questões e a temática fica relegada, quando muito, às parcas aulas de Biologia. Seria preciso que professores e professoras pudessem ser preparados para enfrentar tais questões a partir de um discurso científico crítico e plural.
Mas, o vácuo a que nos referirmos não se opera apenas no âmbito escolar, também na esfera universitária este cenário se apresenta. No currículo dos cursos de Psicologia, há uma ausência significativa destes temas. Partindo do pressuposto de que gênero e sexualidade são elementos que fazem parte fundamental da subjetividade e das relações humanas, torna-se urgente capacitar os acadêmicos dos cursos de ciências humanas para compreender e acolher estes elementos em sua prática profissional.

Todo o cenário acima apresentado indica um contexto controverso. De um lado, um abismal silêncio em torno das questões que envolvem o gênero e a sexualidade. De outro, números que expressam os efeitos deste silêncio através das práticas de violência e assujeitamento. Portanto, este trabalho justifica-se por entendermos que é necessário enfrentarmos este cenário com o objetivo de formar profissionais que estejam aptos para acolher o não dito e o interdito das questões de gênero e sexualidade, mas também para estas sejam pautadas de forma crítica e ética, sempre que necessário.

Por fim, cumpre assinalar um último fato que interfere diretamente no contexto da Psicologia e que ajuda a justificar a necessidade de discutirmos as questões referentes ao gênero e à sexualidade. Recentemente, o juiz federal Waldemar Cláudio de Carvalho produziu uma liminar que determina que o Conselho Federal de Psicologia (CFP) interprete a Resolução $\mathrm{n}^{\circ}$ 01/1999 de modo a não proibir que psicólogas(os) façam atendimento buscando (re)orientação sexual. Assim, a referida liminar buscou enfraquecer a resolução, abrindo brechas para que psicólogas(os) possam oferecer atendimentos de (re)orientação sexual.

A Resolução $\mathrm{n}^{\circ}$ 01/1999 estabelece normas de atuação para os psicólogos em relação à questão da orientação sexual ao afirmar que: "Os psicólogos não colaborarão com eventos e serviços que proponham tratamento e cura das homossexualidades" (Parágrafo único do Art. $3^{\circ}$ ). Importante frisar que a referida resolução surge após a Organização Mundial de Saúde, ainda em 1990, afirmar que as homossexualidades não devem ser classificadas como doença. Assim, a Psicologia brasileira (por meio de seus conselhos profissionais no âmbito regional e federal) vem se organizando e se posicionando contrária à liminar por considerar que não tem embasamento científico, por acreditar que a mesma viola os direitos humanos e por entender que são legítimas as 
orientações sexuais não heteronormativas. Vimos, portanto, que ainda é necessário pautarmos e reafirmarmos todo um modo de a Psicologia se pronunciar sobre tais temas, visto que, de tempos em tempos, há discursos que surgem para desqualificar determinados posicionamentos duramente construídos ao longo de nossa história.

\section{Mapeamento das produções científicas}

Nesta etapa da pesquisa, foi realizado o mapeamento das publicações científicas produzidas no campo das ciências humanas sobre gênero e sexualidade, nas plataformas do SciELO, LILACS e Lattes. Na realização deste momento, nos deparamos com algumas problemáticas: o site LILACS trabalha como uma plataforma de hospedagem, isto é, armazena os links dos trabalhos e direciona para suas respectivas páginas. Isso inclui o direcionamento para o SciELO, o que resultou, em alguns momentos, duplicidade na pesquisa. Assim, foi necessário comparar os resultados de ambas as plataformas para filtrar os artigos e remover os repetidos.

Já a problemática encontrada na plataforma Lattes se deu por aparecerem resultados de autores que não correspondiam com a área das ciências humanas pesquisada, mesmo que os comandos da pesquisa apontassem estas áreas de saber. Assim, chegamos à conclusão de que o Lattes não interliga os dados (área das ciências humanas + tema), pois em alguns momentos, os resultados só respeitaram o tema indicado, mas não a área.

Após o levantamento dos dados e as filtragens acima mencionadas, chegamos aos resultados expostos nos Gráficos 1 e 2.

A partir do resultado, constatou-se que a Educação é a área que mais produz sobre gênero e sexualidade. A Psicologia, que é o foco das investigações, encontra-se na $6^{a}$ posição, o que pode indicar que o interesse de estudo deste campo de saber está pouco relacionado a este tema. Possivelmente, a ausência de disciplinas específicas sobre sexualidade e gênero, temas tratados apenas como transversais na maioria das matrizes curriculares, possa estar relacionado com este dado.

\section{Trabalhos de campo realizados pela Psicologia}

Neste momento da pesquisa, foram analisados todos os trabalhos de campo da Psicologia referentes às temáticas em questão. No que diz respeito à distri-

Publicações Ciências Humanas

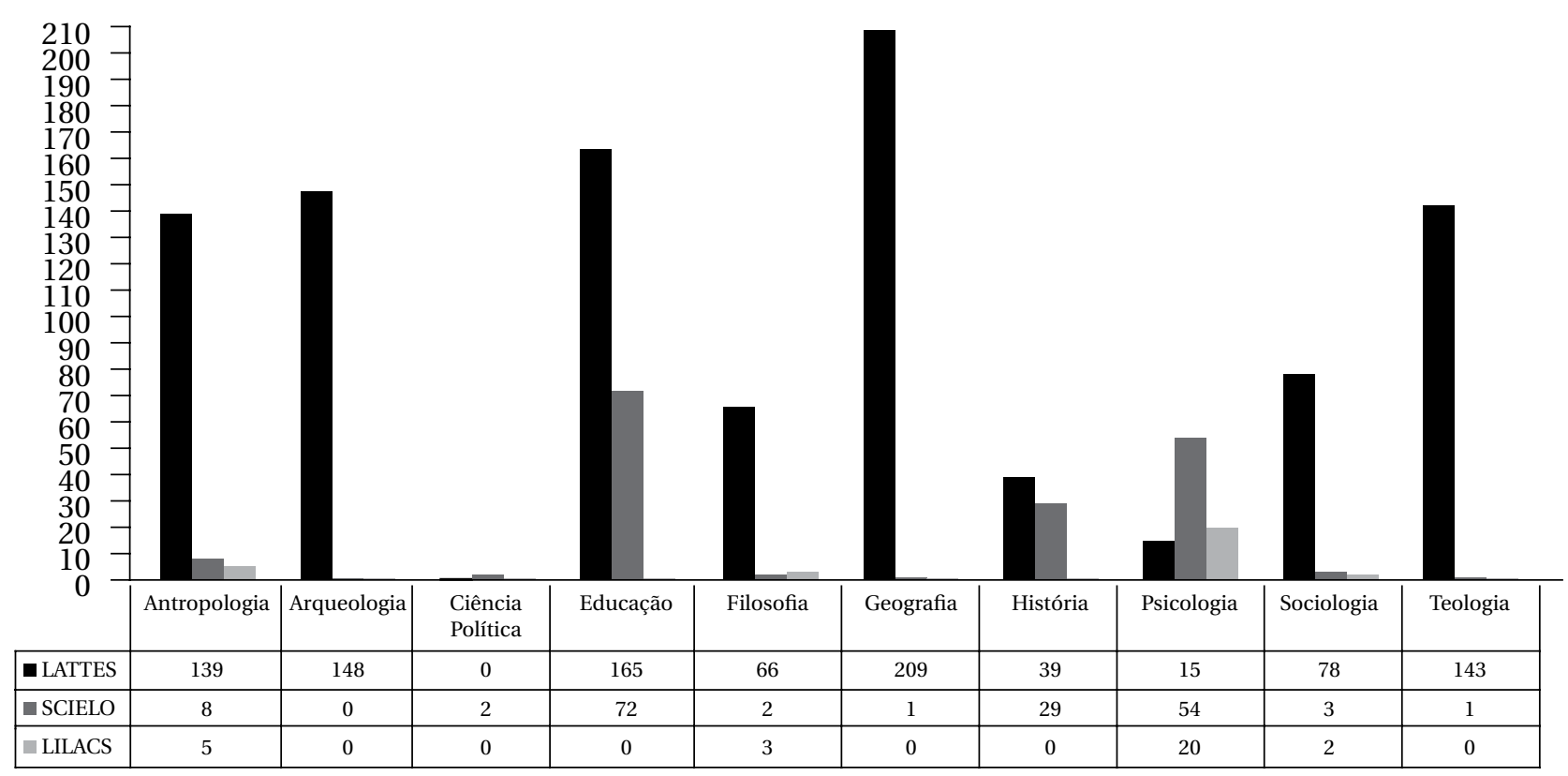

Gráfico 1

Total de publicações por área das Ciências Humanas. 
Total Produções Ciências Humanas

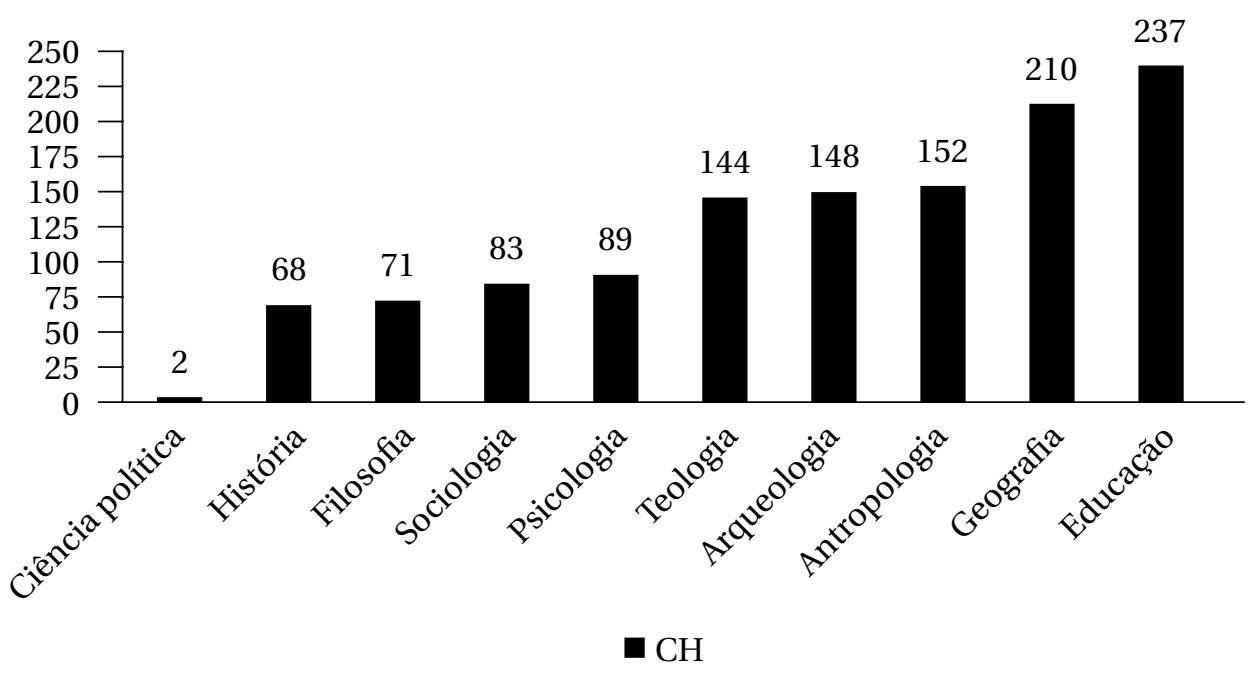

\section{Gráfico 2}

Levantamento do total de produções por área das Ciências Humanas (ranking).

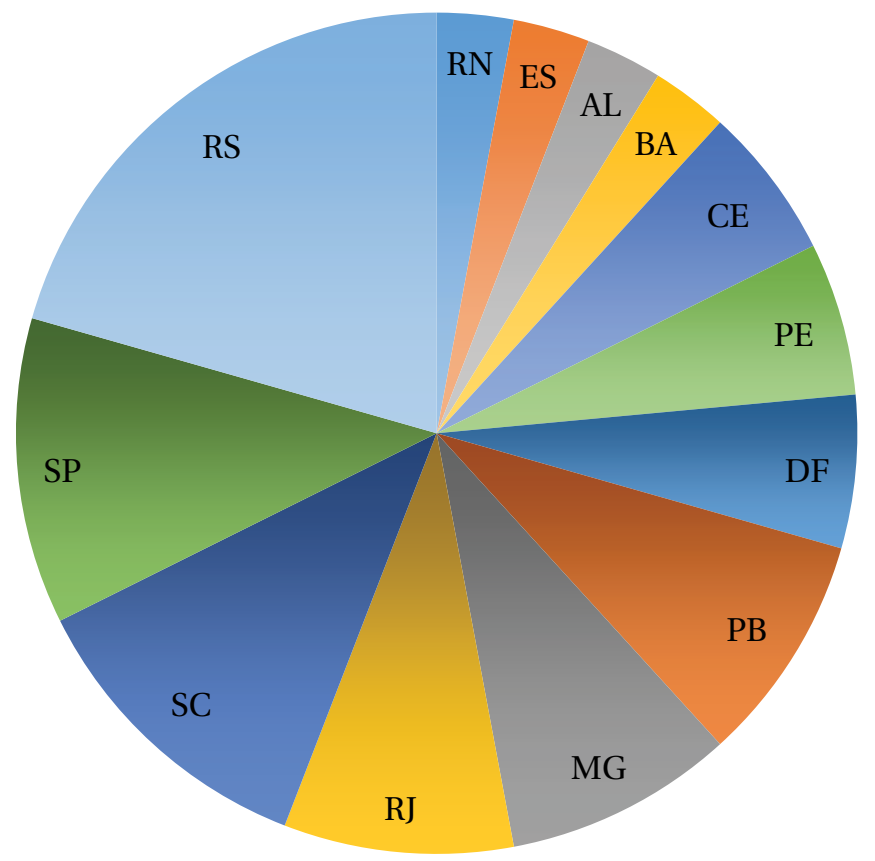

- Rio Grande do Norte

- Espirito Santo

- Alagoas

- Bahia

- Ceará

- Pernambuco

- Distrito Federal

- Paraíba

- Minas Gerais

- Rio de Janeiro

- Santa Catarina

- São Paulo

nio Grande do Sul

\section{Gráfico 3}

Quantitativo do número de publicações por estado.

buição das publicações no solo brasileiro, tem-se o quantitativo que pode ser visualizado no Gráfico 3.

Em relação ao número de publicações por estado, tem-se que o Rio Grande do Sul é o que mais realiza pesquisas de campo sobre gênero e sexualidade $(21 \%$ das publicações brasileiras), totalizando sete produções. Abaixo, encontram-se os estados de São Paulo e
Santa Catarina (12\%), com quatro produções cada. Em seguida, encontram-se os estados do Rio de Janeiro, Minas Gerais e Paraíba (9\%), totalizando três produções cada. Distrito Federal, Pernambuco e Ceará (6\%) contam com duas publicações cada. Os demais estados aparentes no gráfico apresentaram apenas uma produção. 
TEMA

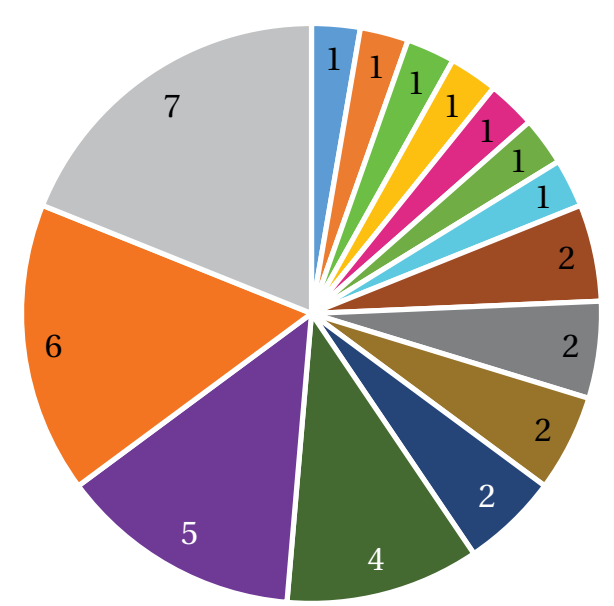

- Gênero

- Saúde

- Sexualidade e Mídia

- Sexualidade e Identidade

- Sexualiade

- Gênero, Sexualidade e Identidade

- Gênero e Saúde

- Gênero e Sexualidade
— Saúde, Gênero e Sexualidade

घ Gênero, Sexualidade, Desenvolvimento e Saúde

- Sexualidade e Educação

- Gênero, Sexualiade e Parentalidade

- Sexualiade e Desenvolvimento

- Gênero, Sexualidade e Desenvolvimento

• Gênero, Sexualidade e Educação

Gráfico 4

Quantitativo dos principais temas dos textos.

Vale salientar que cada artigo foi quantificado a partir do estado em que o primeiro autor estava vinculado no momento da publicação. Percebe-se, portanto, que no cenário nacional as regiões Sul e Sudeste apresentam maior expressividade em termos de publicação. Este número refere-se a maior concentração de programas de pós-graduação nestas localidades, de acordo com o Portal GEOCAPES (https:// geocapes.capes.gov.br/geocapes/).

Obviamente, dentre os 15 grandes temas encontrados (Gráfico 4), "Gênero e Sexualidade" foram os eixos que mais apareceram nas produções, totalizando $19 \%$. No que diz respeito a outros temas convergentes, "Gênero, Sexualidade e Educação" totalizaram 16\%; "Gênero e Saúde" 14\%; "Gênero, Sexualidade e Desenvolvimento", com $11 \%$. Os demais que estão apontados no gráfico contendo duas publicações chegaram ao total de $5 \%$ e os que continham apenas uma produção representou $3 \%$. Novamente, nota-se que o eixo "Educação" se apresenta com mais expressividade na produção brasileira sobre gênero e sexualidade, interligado à Psicologia.

Com relação ao gênero (Gráfico 5), em um universo de 100 autores e coautores, as mulheres predominam nas produções, totalizando $73 \%$. Este dado corrobora com o INFOCAPES, que por meio do Sistema Nacional de Pós-graduação, indica que em 2016, havia um universo de 165.564 mulheres matriculadas e tituladas em cursos de Mestrado e Doutorado, enquanto os homens somam 138.462, uma diferença de cerca de 19\% (Fundação Capes, 2018). Não obstante, este dado também vai ao encontro dos números divulgados pelo CFP, que, em 2012, aponta que as mulheres constituem cerca de $90 \%$ dos profissionais no Brasil (Lhullier, Rosalindo, \& Moreira, 2013).

O método empregado nas pesquisas de campo analisadas (Gráfico 6), predominantemente, é a entrevista, cerca de $46 \%$, totalizando 16 artigos. Os demais ficaram bem abaixo da média, apenas três utilizaram a oficina como caminho metodológico. Os outros 10 
métodos diferentes tiveram apenas duas ou uma utilização nas pesquisas analisadas. Percebe-se, portanto, que a entrevista ainda continua sendo um dos métodos mais empregados na Psicologia atual.

\section{GÊNERO DOS AUTORES}

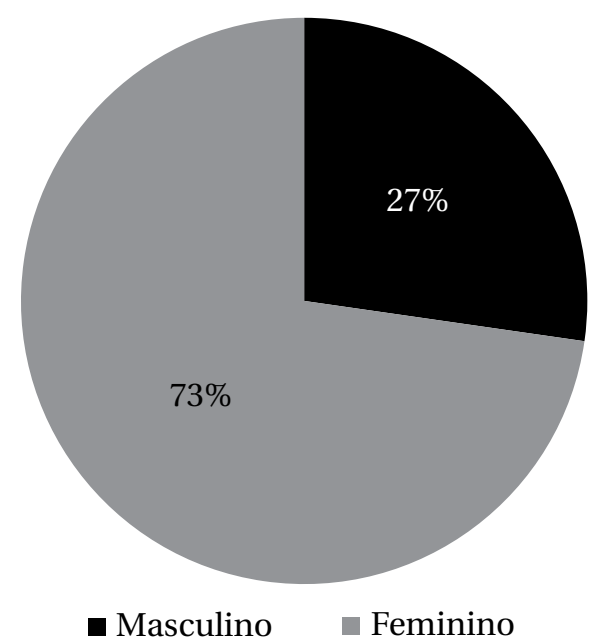

Gráfico 5

Quantitativo do gênero de todos os autores e coautores das produções.
Dentre os artigos analisados, foram elencados os seis grupos mais pesquisados (Gráfico 7). O público de estudantes foi o que apresentou maior expressividade, com cerca de $27 \%$. Em seguida, despontam professores e mulheres, totalizando $19 \%$. Com $15 \%$, surgem as pesquisas que tiveram como público interligado homens e mulheres. Em seguida, 12\% representam as pesquisas com adolescentes. E, por fim, casais, com apenas $8 \%$. A presença de estudantes no topo do ranking corrobora o dado de que, em pesquisas sobre sexualidade e gênero, a Educação predomina como campo de saber com maior expressividade, mesmo sendo ligada ao campo da Psicologia.

\section{Considerações finais}

Buscamos com este artigo compreender de que maneira as temáticas relacionadas ao gênero e à sexualidade estão sendo discutidas nas produções científicas nacionais recentes, tendo como foco principal a Psicologia. Trata-se de uma pesquisa de revisão bibliográfica, realizada através de uma investigação de cunho quantitativo.

A pesquisa aponta para o fato de que cabe à Psicologia um maior empenho para a produção de pes-

\section{METODOS EMPREGADOS}

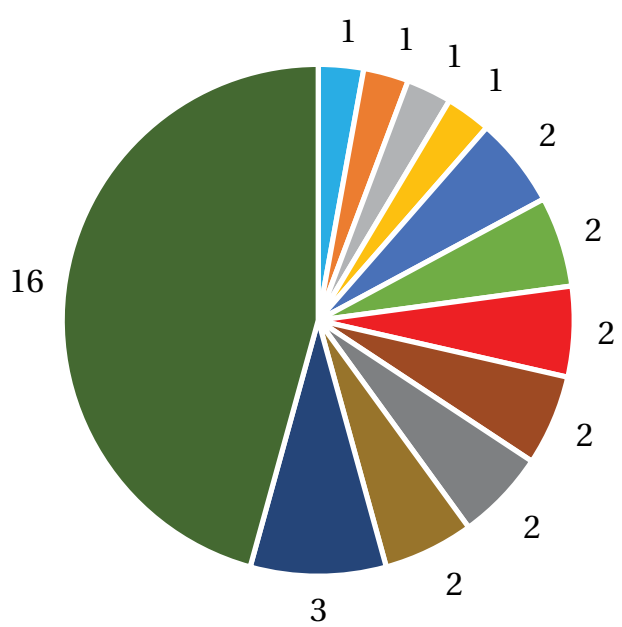

\begin{tabular}{|c|c|c|}
\hline Grupos & - Conversações & Etnografia \\
\hline Pesquisa Exploratória & Investigação & Análise de Discurso/Narrativa \\
\hline - Outra & Escala & • Observação \\
\hline — Questionário & - Oficinas & Entrevista \\
\hline
\end{tabular}

Gráfico 6

Quantitativo do caminho metodológico seguido pelas pesquisas. 


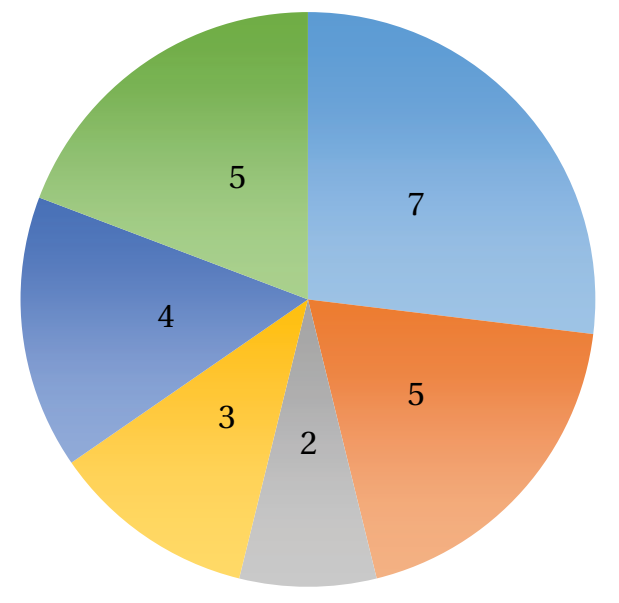

$$
\begin{aligned}
& \text { Estudantes } \\
& \text { Professores } \\
& \text { Casais } \\
& \text { Adolescentes } \\
& \text { Homem e Mulher } \\
& \text { Mulheres }
\end{aligned}
$$

\section{Gráfico 7}

Levantamento do público que foi pesquisado.

quisas que enfrentem as questões de gênero e sexualidade, tendo em vista que são dimensões fundamentais da experiência humana. Para tanto, seria necessário que tais questões pudessem ter maior expressividade no currículo de formação do(a) psicólogo(a).

Importante ainda se faz a realização de pesquisas que contemplem uma maior diversidade de realidades, visto que a grande concentração de programas de pós-graduação nas regiões Sul e Sudeste, acabam por privilegiar a investigação de realidades expressivas destas localidades, ficando a margem destes estudos populações do Norte e Nordeste do país, bem como suas peculiaridades.
Por fim, esta pesquisa aponta para a proximidade científica entre Psicologia e Educação. Logo, de que maneira os saberes psicológicos estão impactando a realidade dos contextos educativos? Na prática, parece haver uma cisão e um diálogo entrecortado entre estas áreas, cenário que se em teoria existe, na prática pouco se expressa. Parece que muitas das bandeiras que interessam à Psicologia - o enfrentamento da LGBTfobia, do machismo e da misoginia - podem se fortalecer num estreito e íntimo diálogo com a Educação, único espaço social realmente capilarizado que atravessa a realidade de inúmeros brasileiros e brasileiras.

\section{Referências}

Brasil (1998). Ministério da Educação. Secretaria de Educação Fundamental. Parâmetros curriculares nacionais: Orientação sexual. Brasilia, DF: o autor.

Brasil, (2016). Relatório sobre violência homofóbica no Brasil: ano de 2013. Brasília, DF: Secretaria de Direitos Humanos.

Butler, J. (2003). Problemas de gênero: Feminismo e subversão da identidade (R. Aguiar, Trad., 3a ed.). Rio de Janeiro, RJ: Civilização Brasileira.

Foucault, M. (1988). História da sexualidade I: A vontade de saber (6a ed.). Rio de Janeiro, RJ: Graal.

Fundação Capes. (2018, 8 de março). Mulheres permanecem como maioria na pós-graduação brasileira. Brasília, DF: o autor. Recuperado de http://www.capes.gov.br/sala-de-imprensa/noticias/8787-mulheres-permanecem-como-maioria-na-pos-graduacao-brasileira

Grupo Gay da Bahia - GGB. (2016). Assassinato de LGBT no Brasil: Relatório 2016. Salvador, BA: o autor. Recuperado de https://homofobiamata.files.wordpress.com/2017/01/relatc3b3rio-2016-ps.pdf

Lhullier, L. A., Rosalindo J. J., \& Moreira, R. A.L. C. (2013). Quem são as psicólogas brasileiras? In Conselho Federal de Psicologia - CFP. Uma profissão de muitas e diferentes mulheres: Resultado preliminar da pesquisa 2012. Brasília, DF: o autor. Recuperado de https://site.cfp.org.br/wp-content/uploads/2013/03/Uma-profissao-de-muitas-e-diferentes-mulheres-resultado-preliminar-da-pesquisa-2012.pdf 
Projeto de Lei no. 867, de 2015. Inclui, entre as diretrizes e bases da educação nacional, o "Programa Escola sem Partido". Recuperado de https://www.camara.leg.br/proposicoesWeb/prop_mostrarintegra;jsessionid=375C72096AFD87644868A98ED8436064. proposicoesWebExterno2? codteor=1317168\&filename=Avulso+$-\mathrm{PL}+867 / 2015$

Resolução CFP No 001/99, de 22 de março de 1999. Estabelece normas de atuação para os psicólogos em relação à questão da Orientação Sexual. Brasília, DF: CFP.

Scott, J. (1995). Gênero: Uma categoria útil de análise histórica. Educação \& Realidade, 20(2), 71-99.

Waiselfisz, J. J. (2015). Mapa da violência 2015: Homicídios de mulheres no Brasil. Brasília, DF: Flacso Brasil. Recuperado de http://www.mapadaviolencia.org.br/pdf2015/MapaViolencia_2015_mulheres.pdf

\section{Tainá Regina de Paula}

Psicóloga pelo Centro Universitário de Mineiros (UNIFIMES). Mineiros - GO. Brasil.

E-mail: tainadpaula@hotmail.com

(iD) https:// orcid.org/0000-0002-1319-9982

Eric de Jesus Porto

Psicólogo pelo Centro Universitário de Mineiros (UNIFIMES). Mineiros - GO. Brasil.

E-mail: eric_jesus11@hotmail.com

(iD https://orcid.org/0000-0002-1932-1870

\section{Cíntia de Sousa Carvalho}

Psicóloga e Psicanalista do Instituto Sedes Sapientiae. São Paulo - SP. Brasil. Doutora e Mestre em Psicologia pela Pontifícia Universidade Católica do Rio de Janeiro (PUC-RJ), Rio de Janeiro - RJ. Brasil. Docente Efetiva do Centro Universitário de Mineiros (UNIFIMES). Mineiros - GO. Brasil.

E-mail: psi.cintiacarvalho@gmail.com

$$
\text { (iD https:// orcid.org/0000-0002-7215-5074 }
$$

Endereço para envio de correspondência:

Rua 18 A, qd. 25, lt. 32, casa 04. Setor Aeroporto. Mineiros - GO. Brasil.

Recebido $11 / 09 / 2019$

Aceito 04/10/2019

Received 09/11/2019

Approved 10/04/2019

Recibido 11/09/2019

Aceptado 04/10/2019

Como citar: Paula, T. R., Porto, E. J., \& Carvalho, C. S. (2019). Um sobrevoo pelo estado da arte sobre gênero e sexualidade na pesquisa. Psicologia: Ciência e Profissão, 39 (n.spe 3), 194-205. https://doi.org/10.1590/1982-3703003228573

How to cite: Paula, T. R., Porto, E. J., \& Carvalho, C. S. (2019). An overview of the state of the on gender and sexuality in research. Psicologia: Ciência e Profissão, 39 (n.spe 3), 194-205. https://doi.org/10.1590/1982-3703003228573

Cómo citar: Paula, T. R., Porto, E. J., \& Carvalho, C. S. (2019). Un sobrevuelo por el estado del arte sobre género y sexualidad enlainvestigación.Psicologia:CiênciaeProfissão,39(n.spe3),194-205.https://doi.org/10.1590/1982-3703003228573 